\title{
ENCONTROS E DESLOCAMENTOS EM ENSAIOS DE NANCY HUSTON
}

\author{
Claudia Maria Pereira Almeida
}

\author{
Como toda obra literária, o ensaio está no campo da ficção. \\ Seu discurso é um discurso opaco, não porque abrange as coisas, \\ mas porque substitui as palavras à realidade. ${ }^{1}$
} (TERRASSE, 2003, p. 106)

No trecho que serve de epígrafe a este artigo, Jean Terrasse simplifica uma das questões que envolvem a conceituação do ensaio, ou seja, a sua natureza literária. Na verdade, a tentativa de balizamento do território ensaístico apresenta um grau de complexidade alto, na medida em que uma grande diversidade de discursos e interseções com outros gêneros textuais conferem ao ensaio um caráter polimorfo, que tornam insuficientes as tipologias. ${ }^{2}$

Para refletirmos sobre esse tema, usaremos como corpus textos de Nancy Huston, escritora cuja carreira literária se inicia precisamente pelo gênero ensaio, em 1979, com a publicação de Jouer au papa et à l'amant. De l'amour des petites filles [Brincar de papai e namorado. Sobre o amor das garotinhas]. Atualmente, a autora canadense, que se mudou para a França em 1973, contabiliza uma obra extensa e multifacetada: romances, relatos, peças teatrais, ensaios, correspondências, textos em parcerias com

\footnotetext{
1 "Comme toute oeuvre littéraire, l'essai relève de la fiction. Son discours est un discours opaque, non parce qu'il embrasse des choses, mais parce qu'il substitue les mots à la réalité." Salvo indicação específica, as traduções deste artigo são nossas.

${ }^{2}$ A respeito de tipologias do gênero ensaio, remetemos ao artigo "Remarques sur l'essai littéraire" [Observações sobre o ensaio literário], de Marc Angenot (2003), e ao livro de Robert Vignault (1994), L'écriture de l'essai [A escrita do ensaio].
} 
artistas plásticos e fotógrafos, livros infanto-juvenis, contos publicados em antologias, traduções de obras do inglês para o francês, prefácios, posfácios, discos com leituras de textos próprios e artigos publicados em jornais e revistas. Se seguimos a lista das obras da autora e sua respectiva classificação, ${ }^{3}$ chegamos a um total de 17 ensaios, aí incluídas as três coletâneas publicadas até o presente. No conjunto de sua obra, o ensaio é o gênero em que mais investiu, seguido pelo romance, com 14 títulos.

Apesar dos números, não podemos afirmar que Nancy Huston tem uma preferência por esse gênero. A leitura e a análise de sua produção apontam para a escrita de textos que criam interfaces entre gêneros e linguagens. Assim, os volumes classificados como correspondências também são reconhecidos como ensaios pela própria escritora: "Em 1984, eu havia publicado, em forma de correspondência com o historiador Samuel Kinser, um ensaio intitulado No amor como na guerra" (HUSTON, 2007, p. 94).4 A coexistência de dois gêneros, carta e ensaio, não é original; por exemplo, Lukács (2008) o faz, ao discutir a forma e a essência do ensaio, em uma carta dirigida a Leo Popper. Entretanto, essa coexistência de dois ou mais gêneros parece ser uma escolha e uma busca da escritora. Como discutiremos nas seções seguintes, alguns ensaios de Nancy Huston são construídos a partir de uma pluralidade de vozes, citações, autocitações, reflexões e opiniões que contribuem decisivamente para a construção de formas compósitas que, no entanto, não perdem o caráter ensaístico.

É curioso observar que o espaço do ensaio nem sempre foi priorizado pela escritora. Em outro livro de correspondência, ela afirma:

Mas, como você [Leïla Sebbar], me sinto cada vez menos à vontade no ensaio, por menos convencional que seja a forma. Não gosto de ter que levar o leitor pela mão, mostrar como o ponto B de minha demonstração decorre logicamente do ponto A... Quanto à ficção, trata-se de um mundo de uma liberdade tão absoluta que chega a ser assustador, e inventar, você mesma, leis para reduzir essa liberdade é uma atividade atordoante (HUSTON, 1986, p. 144). ${ }^{5}$

\footnotetext{
3 Não encontramos uma lista completa das publicações de Nancy Huston. A escritora não tem um site pessoal, e as editoras Actes Sud (Paris) e Leméac (Montreal), pelas quais publica a maioria de suas obras na França e no Canadá, respectivamente, não apresentam essa lista em seus sites. Os quantitativos indicados decorrem de consultas às “Obras da autora”, referenciadas em alguns de seus livros, e a pesquisas que desenvolvemos desde 2000.

4 "En 1984 j'avais publié, sous forme de correspondance avec l'historien américain Samuel Kinser, un essai intitulé A l'amour comme à la guerre."

5 "Mais, comme toi, je me sens de moins en moins à l'aise dans l'essai, si non conventionnelle que soit sa forme. Je n'aime pas avoir à mener le lecteur par la main, à lui montrer comment le point B de ma démonstration découle logiquement du point A... Quant à la fiction, c'est
} 
Esse desconforto parece ter sido passageiro, pois a produção ensaística de Nancy Huston nunca foi interrompida. Após o livro citado acima, a autora publica um romance - Trois fois septembre (1989) - e um ensaio - Journal de la création (1990). Essa alternância entre ensaio e romance prossegue até os dias atuais, com a inclusão, todavia, de outros gêneros. A produção ensaística de Nancy Huston, no entanto, em muitos momentos, aproxima-se da ficção, seguindo um discurso semelhante ao descrito por Jean Terrasse, na citação que colocamos em epígrafe.

Neste artigo, vamos nos concentrar no estudo de dois ensaios: Tombeau de Romain Gary (1995) e Passions d’Annie Leclerc (2007). O critério que definiu essa escolha foi a identificação de traços peculiares desses textos no conjunto da produção ensaística da autora, dentre os quais uma escrita que favorece e privilegia incursões no campo ficcional. Antes de refletirmos especificamente sobre o corpus, retomamos algumas contribuições teóricas importantes sobre o gênero ensaio, que serão ferramentas ou esteio para nosso trabalho.

\section{FRAGMENTOS DE UM MOSAICO}

Pouco mais de um século após a impressão do primeiro livro por Gutenberg, Montaigne publica, em 1580, seus Ensaios, que se constituem, até hoje, como uma referência importante para os estudos sobre o gênero. Mas, na França, sua relevância é ainda maior, pois essa obra desempenhou papel fundamental na consolidação do francês enquanto língua escrita. Seu caráter sério, que transforma em texto escrito reflexões de cunho prioritariamente filosófico, comprova que a língua francesa é capaz de expressar ideias consistentes, função que, até então, era desempenhada quase que exclusivamente pelo latim.

Ao longo do tempo, o ensaio vem se transformando e também se tornando objeto de estudo. Não pretendemos fazer um retrospecto exaustivo desses aportes teóricos, ${ }^{6}$ mas sim destacar alguns posicionamentos que nos parecem essenciais para a compreensão das transformações por que passou esse gênero, sobretudo no que diz respeito à sua vocação para a multiformidade e às suas interfaces com o romance. Desse modo, selecionamos alguns pensadores

un monde d'une liberté si absolue que c'en est terrifiant, et inventer soi-même des lois pour réduire cette liberté est une activité vertigineuse."

${ }^{6}$ Para uma lista extensa de títulos sobre o ensaio, consultar a tese de Irène Langlet (1995). 
cujos estudos e produções ensaísticas destacam aspectos que julgamos importantes para refletirmos sobre nosso corpus. Não propomos, contudo, uma análise minuciosa de suas obras; com efeito, para construirmos um mosaico que será o pano de fundo de nossa reflexão, separamos algumas questões que esses autores desenvolvem. Evidentemente, a lista dos ausentes é longa, e enumerá-los seria temerário.

A primeira peça nessa composição que propomos é precisamente o texto de Michel de Montaigne. Na primeira página do volume 1 dos Ensaios, dirigida ao leitor, o autor expressa suas intenções, declarando:

Prefiro, porém, que me vejam na minha simplicidade natural, sem artifício de nenhuma espécie, porquanto é a mim mesmo que pinto. Vivos se exibirão meus defeitos e todos me verão na minha ingenuidade física e moral, pelo menos enquanto o permitir a convivência (MONTAIGNE, 1996, p. 31).

O subjetivismo consciente, presente nessa obra de referência para o gênero ensaio, permanecerá no decorrer do tempo como uma de suas características mais marcantes. O posicionamento do escritor que assume a condição de experimentalidade de sua reflexão será bastante recorrente nos escritos ensaísticos até os dias de hoje. Na verdade, a escrita ensaística é fortemente marcada por uma liberdade de escolhas que renuncia às certezas e investe na construção de possibilidades. Essa busca permanente por caminhos, que se interrompe antes da chegada, é a segunda característica, do texto de Montaigne, que subsiste no ensaio contemporâneo. No divertido ensaio Sobre Demócrito e Heráclito, em que comenta as posturas não somente dos filósofos mencionados no título, mas também de outros personagens da Antiguidade Romana, o pensador francês afirma:

É o juízo um instrumento útil em tudo. Estes ensaios me fornecem amiúde a oportunidade de empregá-lo. Se não entendo de algum tema, recorro a ele e o ponho à prova, com ele sondando o vau. E se verifico ser este demasiado profundo, fico na margem. E o reconhecimento de que não posso ir além é um dos serviços que me presta e de que mais se orgulha. Por vezes, quando o assunto é fútil procuro ver a que ponto lhe dará consistência, apoio e alicerce. E se ventilo coisa importante e já batida, ele me ajuda a descobrir o melhor desses caminhos, tão frequentados que já não há como o evitar. E entre mil veredas diferentes indica a que devo seguir. Ao acaso escolho um assunto, pois todos me são igualmente bons e não pretendo esgotar nenhum, porquanto de nenhum chego a ver o fundo. E os que nos prometem mostrá-lo não cumprem suas promessas (MONTAIGNE, 1996, pp. 266-267). 
O juízo [jugement] - ou seja, a "faculdade de avaliar os seres e as coisas" (HOUAISS; VILLAR, 2001, p. 1.690) - é apresentado como o principal instrumento para a escrita dos ensaios. É a partir dessa avaliação pessoal que serão definidos o percurso e os limites da reflexão. Assim, é essa apreciação que estabelecerá os momentos de interrupção - quando o assunto é "fútil" - e de encerramento - quando o ensaísta fica na "margem". Ao destacar que não pretende esgotar nenhum tema, Montaigne se arroga o direito de não "chegar ao fundo" de matéria alguma tratada em seus ensaios. Essa incompletude, vista com naturalidade pelo pensador, valoriza o percurso reflexivo em detrimento da conclusão categórica.

Quatro séculos mais tarde, em 1910, o filósofo húngaro György Lukács estuda as características do ensaio ressaltando algumas mudanças observadas nesse gênero. Trata-se de "Sobre a essência e a forma do ensaio", carta dirigida a Leo Popper. Nesse texto, argumentando pela negação, Lukács (2008, p. 2) aponta um aspecto fundamental de sua visão do ensaio: é preciso "que tenhamos presentes apenas os verdadeiros ensaios e não aqueles escritos úteis, porém injustificadamente assim denominados, que não nos podem oferecer nada além de ensinamentos e dados e 'conexões'”. Assim, textos que se restringem ao nível da informação não poderiam ser incluídos dentro do gênero. $\mathrm{O}$ ensaio busca uma reflexão sobre o texto literário ou sobre determinados temas sem rivalizar com este, ou seja, a escritura ensaística se constrói sobre o texto literário, mas não se trata de complementação, e sim de produção de sentidos a partir de outro texto ou a partir de um tema.

Lukács (2008, p. 11) ainda identifica uma mudança de estatuto, advinda na modernidade:

O ensaio moderno, afinal, não fala de livros e poetas - mas esta salvação o torna ainda mais problemático. Ele se coloca em uma altura demasiada, sua visada abrange e articula coisas demais, o que o impede de ser a representação e a explicação de uma obra; cada ensaio escreve com letras invisíveis ao lado de seu título as palavras: por ocasião de... Ele se tornou, portanto, rico e independente demais para ser um abnegado servidor, mas também intelectual e multiforme demais para obter de si mesmo uma forma. Não se terá tornado também ainda mais problemático e ainda mais distanciado do valor da vida do que se dissertasse fielmente sobre livros? [...]

Agora o ensaísta tem de refletir sobre si mesmo, encontrar-se e construir algo próprio com o que lhe é próprio.

A independência adquirida faz com que o ensaio deixe de ser um acompanhante, um texto sobre outro, e se bastea si mesmo. A força do texto 
de referência ou do tema desenvolvido é esvaziada em favor da escritura produzida. Dessa forma, o ensaio está inserido na escritura barthesiana, que não tem origem nem fim predefinidos, mas que se constrói no tecer da trama. Essa autonomia também promove um clareamento das linhas que demarcam o gênero, favorecendo uma escrita compósita que sublinha a disposição experimental e o impulso criativo do ensaio.

Algumas décadas mais tarde, entre 1954 e 1958, Theodor Adorno também escreve sobre o ensaio e retoma o texto de Lukács (TIEDEMANN, 2003, p. 163), dele discordando em alguns pontos. Adorno destaca o caráter individual e novo do ensaio, caráter este que não é parte de ideias preconcebidas nem segue um método definido. Essa tendência à indisciplina e, de certa forma, à rebeldia confere ao ensaio um quê de heresia: desligando-se do texto que comenta, o ensaio se bastaria a si mesmo.

Entretanto, essa independência não daria ao gênero o estatuto de forma artística. Segundo Adorno (2003, p. 18), Lukács comete um equívoco ao incluir o ensaio dentro da categoria artística, pois tanto os instrumentos quanto os objetivos seriam diferentes:

\begin{abstract}
Nada se deixa extrair pela interpretação que já não tenha sido, ao mesmo tempo, introduzido pela interpretação. Os critérios desse procedimento são a compatibilidade com o texto e com a própria interpretação, e também a sua capacidade de dar voz ao conjunto de elementos do objeto. Com esses critérios, o ensaio se aproxima de uma autonomia estética que pode ser facilmente acusada de ter sido apenas tomada de empréstimo à arte, embora o ensaio se diferencie da arte tanto por seu meio específico, os conceitos, quanto por sua pretensão à verdade desprovida de aparência estética. É isso o que Lukács não percebeu quando, na carta a Leo Popper que serve de introdução ao livro $A$ alma e as formas, definiu o ensaio como uma forma artística.
\end{abstract}

Apontando como características do ensaio a manipulação de conceitos e a ambição de alcançar a verdade, Adorno lhe recusa espaço no campo da arte. Contudo, pouco antes desse trecho, também destaca traços que o aproximam de escritas literárias:

Felicidade e jogo lhe são essenciais. Ele não começa com Adão e Eva, mas com aquilo sobre o que deseja falar; diz o que a respeito lhe ocorre e termina onde sente ter chegado ao fim, não onde nada mais resta a dizer: ocupa, desse modo, um lugar entre os despropósitos (ADORNO, 2003, p. 17).

Ao identificar o caráter lúdico e descompromissado do ensaio, o filósofo alemão ressalta certa insuficiência formal para classificá-lo em um campo específico, seja na ciência, seja na arte. De fato, o único traço que aproximaria 
o ensaio da arte seria a liberdade em relação à apresentação de seu objeto. Aproximação, todavia, insatisfatória para a entrada no campo artístico.

Adorno (2003, p. 35) ainda destaca o caráter fragmentário do gênero: "A descontinuidade é essencial ao ensaio; seu assunto é sempre um conflito em suspenso". Essa fragmentação reflexiva muitas vezes repercute na forma que, metonimicamente, também se desagrega.

Na mesma década em que Adorno escreve e publica esse texto, Roland Barthes publica seu primeiro livro, Le degré zéro de l'écriture [O grau zero da escrita], em 1953. O pensador desempenha papel fundamental na constituição do gênero ensaio. Sua extensa obra está majoritariamente localizada no espaço ensaístico, com reflexões e experimentações que ampliam seus limites e estabelecem interfaces com outros gêneros. Em 1977, em sua aula inaugural da Cadeira de Semiologia Literária, no Collège de France, Barthes ([s.d.], p. 4) declara: "E se é verdade que, por longo tempo, quis inscrever meu trabalho no campo da ciência, literária, lexicológica ou sociológica, devo reconhecer que produzi tão somente ensaios, gênero incerto onde a escritura rivaliza com a análise".

A constatação de ter escrito apenas ensaios poderia sugerir uma visão hierarquizada dos gêneros literários, na qual o ensaio não estaria em primeiro lugar. Mas tal não ocorre. Na verdade, o apenas de Barthes parece remeter ao desejo não realizado, como aponta o título de seu último e inacabado seminário no Collège de France: "Preparação para o romance". Romance este que nunca se realizou plenamente, mas cujo espectro ronda a obra barthesiana. No texto "Durante muito tempo fui dormir cedo", Barthes (1988, p. 284) estuda a hesitação de Marcel Proust entre esses dois gêneros, definindo diferentes figuras retóricas como esteio para cada um:

A Metáfora suporta todo discurso que levanta a questão: "O que é? O que é que isso quer dizer?”; é a questão mesma do Ensaio. A Metonímia, ao contrário, levanta outra questão: "De que isto que estou anunciando pode ser seguido? O que é que o episódio que estou a contar pode gerar?”; é a questão do Romance.

A oposição entre essas figuras, explicitamente inspirada em Roman Jakobson, revela-se menos rigorosa do que se poderia supor, assim como os lados que haviam sido percebidos pelo narrador como opostos, no texto proustiano, mostram-se vizinhos, "o lado da casa de Swann toca o lado de Guermantes” (BARTHES, 1988, p. 284). O ensaísta francês confirma, pois, que os territórios do ensaio e do romance têm galerias de comunicação e, até mesmo, caminhos compartilhados. 
Em Comment parler à la littérature avec Roland Barthes, conferência de abertura do "Colóquio Avec Roland Barthes", por ocasião do centenário de nascimento do pensador, Julia Kristeva (2015), 7 discorrendo sobre Fragmentos de um discurso amoroso, afirma que esse texto seria o mais limítrofe de Barthes: "Jamais Barthes esteve tão próximo do romance, mas sem transpor o limiar. Diria que ele figura a interpretação onde o romancista narra". ${ }^{8}$ Nesse sentido, a aproximação entre ensaio e romance na escrita barthesiana também corrobora a impressão de Claire de Obaldia (2005, p. 273) que caracteriza essa escrita como "prefacial", sempre anunciando outra que, no entanto, talvez não tenha vindo. No território de experimentações do ensaio, Barthes se desloca entre hesitações e oscilações que atestam a fluidez das fronteiras do gênero e confirmam sua multiformidade.

Em 1982, Jean Starobinski, em seu discurso por ocasião do recebimento do Prêmio Europeu do Ensaio - concedido pela Fundação Charles Veillon para seu livro Montaigne en mouvement (1982) -, estuda o gênero e destaca na etimologia da palavra dois sentidos que estabelecem a oscilação que serve de guia para grande parte dos ensaios, ou, pelo menos, para os textos que, segundo o autor, merecem essa classificação.

Essai, conhecido em francês desde o século XII, provém do baixo latim exagium, a balança; ensaiar deriva de exagiare, que significa pesar. Nas proximidades desse termo se encontra examen: agulha, lingueta do fiel da balança, e, por extensão, exame ponderado, controle. Mas um outro sentido de "exame" designa o enxame de abelhas, a revoada de pássaros. A etimologia comum seria o verbo exigo, forçar para fora, expulsar, e daí exigir. Quantas tentações, se o sentido nuclear das palavras atuais devesse resultar do que elas significaram num passado longínquo! O ensaio seria a pesagem exigente, o exame atento, mas também o enxame verbal cujo impulso se libera (STAROBINSKI, 2011, pp. 13-14).

A oscilação entre rigor e vivacidade, entre o saber conhecido e o desconhecido é também familiar a Montaigne. Em 1576 (quatro anos antes da publicação do primeiro e do segundo volumes dos Essais), manda gravar em uma medalha a figura de uma balança e a divisa "Que sais-je?".

O teórico suíço propõe como balizas para a escrita do ensaio a reflexão severa e o pulular de ideias. No território instável entre essas referências, não

\footnotetext{
${ }^{7} \mathrm{O}$ trecho citado foi transcrito a partir do vídeo, já que não encontramos a mesma versão publicada.

8 "Jamais Barthes n’a été aussi près du roman, mais sans franchir le seuil. Je dirais qu'il figure l'interprétation là où le romancier raconte."
} 
encontraremos conclusões definitivas, mas sim discussão de ideias. Esse, aliás, é um aspecto fundamental para entender a especificidade do gênero: "literatura de ideias no sentido mais literal do termo: literatura feita com ideias" (VIGNEAULT, 1994, p. 21). ${ }^{9}$

Esses fragmentos de reflexões sobre o ensaio não encerram a questão do gênero, mas constituem peças de destaque em um grande mosaico bibliográfico. Também nos servirão como instrumentos para adentrar túmulos e descortinar afetos nos ensaios de Nancy Huston.

\section{O ENSAIO DO TÚMULO}

O Tombeau de Romain Gary é um marco na escrita ensaística de Nancy Huston (1995). Quinto ensaio estendido ${ }^{10}$ da escritora, esse texto reúne características e estratégias que serão retomadas nos ensaios posteriores, especialmente no que diz respeito a encontros e deslocamentos no espaço ensaístico.

O título, Tombeau de Romain Gary, remete a um gênero literário bastante usual no século XVI, na França e em outros países europeus. De acordo com Philippe Van Tieghem (1984), o túmulo se configura como um texto de caráter laudativo, escrito em homenagem a um indivíduo ilustre falecido. Frequentemente, túmulo também se refere a uma coletânea de textos desse tipo. Esse gênero se tornou raro nos séculos XVII e XVIII, mas, no século XIX, Stéphane Mallarmé o resgata, transformando-o: ultrapassando a ideia de homenagem, o escritor o utiliza como lugar de "afirmação de um estatuto particular para o poeta, fora do mundo social, na margem, por ser ignorado, e à margem pela recusa" (MONCOND'HUY, 1994, p. 8)." Esse resgate mallarmeano segue o caminho de uma "reivindicação - ainda que dolorosa - de uma autonomia, de um estatuto novo para o poeta, que só busca reconhecimento e legitimação junto a seus pares e aos letrados" (p. 8). ${ }^{12}$ No século XX, vários túmulos são publicados na França, mas essa produção é

\footnotetext{
9 "Littérature d'idées, au sens le plus littéral du mot: littérature faite avec des idées."

${ }^{10}$ Seguimos a classificação de Gérard Genette (2002), que define o ensaio estendido como aquele que pode ocupar um volume inteiro, enquanto o ensaio breve seria publicado apenas em coletâneas.

"11 "Affirmation d'un statut particulier pour le poète, en dehors du monde social, en marge parce qu'ignoré, et en marge par refus."

12 "Revendication - fût-elle présentée comme douloureuse - d'une autonomie, d'un statut nouveau pour le poète, qui ne cherche plus reconaissance et légitimation qu'auprès de ses pairs et des lettrés."
} 
fortemente heterogênea e seria excessivo reconhecermos um renascimento do gênero. Na verdade, percebemos o túmulo como mais uma possibilidade de ruptura de limites entre os gêneros, bastante observada ao longo do século passado.

No túmulo escrito por Nancy Huston, a combinação de características de diferentes gêneros tem como resultado um texto compósito, no qual reverberam rumores barthesianos de biografia, ensaio, romance e túmulo. A leitura da obra de Romain Gary é apresentada pela escritora como liberadora: "Foi Romain Gary que, por sua magia, sua capacidade de encantamento, sua inventividade, sua recusa da realidade bruta, me liberou de Barthes, de Sarraute e de Robbe Grillet" (HUSTON, 2001, p. 31). ${ }^{13}$ Metonimicamente, a escrita de um túmulo também a libera para transitar em diferentes territórios, deslocando e apagando fronteiras. No Tombeau, o percurso cronológico de acontecimentos importantes da vida do escritor lituano flerta com a biografia; a homenagem do túmulo é assegurada pela apropriação do texto escrito de Romain Gary e pela transformação desse último em texto, perpetuando sua obra através de sua reescrita e de sua continuação (ALMEIDA, 2004); o uso amplo do juízo a que se refere Montaigne, o desenvolvimento de uma reflexão rigorosa, que se permite, no entanto, brincar com o personagem escritor, são fios que se entrelaçam na enunciação de um sujeito que se põe em jogo no espaço ensaístico; a representação de uma "ordem afetiva”, do movimento de um dizer transitivo indireto, ou seja, dizer àqueles que se ama, e não apenas que são amados, moderadamente desvelada no Tombeau, evoca o romance idealizado por Barthes (1988).

A estrutura do Tombeau de Romain Gary surpreende o leitor que tinha a expectativa de um ensaio ou de um túmulo. Desde o início, a autora cria um ambiente dialógico, dirigindo-se diretamente ao escritor e usando o pronome você. Esse ambiente dialógico também é constituído pela voz que Nancy Huston atribui a Gary, tanto em citações indiretas quanto diretas. As perguntas quase retóricas recebem uma resposta do escritor, que é contestada pela autora, como no exemplo a seguir:

Nunca, nenhuma raiva, nenhuma revolta, contra esse escandaloso controle maternal da tua existência, nunca realmente? Mesmo durante os anos de colégio em Nice, quando, alegando que você era Victor Hugo, Nina, publicamente, em sua "língua de carroceiro", passava uma descompostura nos professores que te

13 “C'est Romain Gary qui, par sa magie, sa capacité d'enchantement, son inventivité, son refus de la réalité brute, m’a libérée de Barthes, de Sarraute et de Robbe-Grillet.” 
davam notas ruins? Mesmo aos vinte e quatro anos, quando tendo ido morar em Paris para fazer o curso de Direito, você publicou os primeiros contos, que ela brandia nas fuças dos vendedores de legumes no mercado da rua Buffa? Mesmo nos anos de treinamento na aviação, quando ela telefonava a toda hora para te azucrinar com seus conselhos? Não; nunca; aparentemente. Veremos (HUSTON, 1995, p. 23). ${ }^{14}$

O diálogo fabricado se estabelece com um personagem também fabricado. Essa pergunta da enunciadora do Tombeau dialoga, na verdade, com um dos livros mais conhecidos de Romain Gary (2008), La promesse de l'aube [Promessa ao amanhecer], de 1980.15 Nesse texto, o escritor apresenta uma autobiografia romanceada, na qual a figura de sua mãe é particularmente enaltecida e mitificada. O Romain Gary a quem se refere o tu/você do Tombeau é o produto de seus textos, do ethos construído em entrevistas, do escritor/texto estudados pela crítica literária francesa e da leitura e do juízo de Nancy Huston. Trata-se de um certo Romain Gary, que a autora, ao mesmo tempo, admira e rejeita, e com quem compartilha a opção pela escrita em língua estrangeira, assim como o sentimento de impostura, de medo e de estrangeiridade decorrente dessa escolha, e uma "empatia desesperada" com os mais fracos (HUSTON, 2014a).

É preciso ressaltar, contudo, que a construção desse personagem se fundamenta em elementos realmente biográficos. Apesar de reconhecer que Romain Gary havia mentido "de modo inveterado, desavergonhado, soberbo" (HUSTON, 1995, p. 12) ${ }_{1}^{16}$ o que transforma a escrita da vida autor em uma difícil empreitada, a enunciadora segue, no Tombeau, um percurso cronológico, selecionando fatos e textos que servem de esteio para seus comentários. Posteriormente, ela admite ter cometido algumas “inexatidões" (HUSTON, 2014b, p. 239) devido às informações imprecisas sobre o escritor, disponíveis quando escreveu o Tombeau. O uso de dados biográficos é usual

\footnotetext{
${ }_{14}$ "Jamais aucune colère, aucune révolte, vraiment, contre cette scandaleuse mainmise maternelle sur ton existence? Même pendant tes années de lycée à Nice, quand, sous pretexte que tu étais Victor Hugo, Nina enguirlandait en public, dans 'son langage de charretier', les professeurs qui te donnaient de mauvaises notes? Même à l'âge de vingtquatre ans lorsque, monté à Paris pour étudier le droit, tu as fait paraître tes toutes premières nouvelles et qu'elle est allée les brandir sous le nez des vendeurs de légumes, au marché de la Buffa? Même pendant tes années d'entraînement dans l'aviation, quando elle te téléphonait à tout bout de champ pour te harceler de ses conseils? Non; jamais; apparemment. On verra."

${ }^{15}$ A data remete à edição definitiva do texto publicado originalmente em 196o. Esse texto foi traduzido em português e publicado com o título Promessa ao amanhecer.

16 "[...] de façon invétérée, éhontée, superbe."
} 
no túmulo, mas não como fio condutor, já que o primeiro objetivo desse gênero é a exaltação do indivíduo e de seus atos. Justamente, o balizamento cronológico inclui fatos e feitos pouco louváveis da vida de Romain Gary, que são discutidos pela enunciadora. Apesar de não ser uma biografia do escritor, a estrutura do Tombeau apresenta, também, um arcabouço biográfico.

Às oscilações entre biografia e túmulo, podemos acrescentar o movimento ensaístico que é norteado pelo juízo da enunciadora. Essa construção textual tem como base um estudo sistemático e amplo da vida e da obra de Romain Gary, como explicita Nancy Huston (1995, p. 11), no segundo parágrafo do texto: "Agora, já são quase dois anos durante os quais eu esquadrinho, por todos os lados, tua obra e me questiono sobre tua vida". ${ }^{17} \mathrm{O}$ caráter ensaístico perpassa o texto do alicerce à cobertura, constituindo-se como principal material da argamassa que assenta tijolos e blocos, permanecendo visível na construção.

Em uma das muitas entrevistas concedidas por Nancy Huston (2014b, p. 239), as quais têm como tema o Tombeau e a leitura da obra de Romain Gary, a escritora esclarece:

[Decout:] - Gary é o autor de uma espécie de "túmulo" para sua mãe com Promessa ao amanhecer, uma homenagem que também é uma ressurreição. Por que você escolheu o mesmo gênero? Chegou a pensar em uma analogia com Promessa ao amanhecer?

[Huston:] - Não necessariamente. O título só me veio em um segundo momento. É verdade que, com a ideia de túmulo, eu também pensava em Rameau, entre outros. É ao mesmo tempo uma homenagem e uma maneira de enterrá-lo de outra forma. ${ }^{18}$

O gênero túmulo parece não ter sido uma escolha prévia, embora tenha sido, de fato, incorporado na escrita. A proposta dupla de homenagem e enterroacrescenta uma dosedeironia, já que Romain Gary nunca foi enterrado. Seguindo as instruções deixadas pelo escritor, ele foi cremado e suas cinzas foram jogadas no Mediterrâneo. Ao "enterrá-lo de outra forma”, Nancy Huston, na verdade, o enterraria pela primeira vez.

\footnotetext{
${ }_{17}$ "Voilà près de deux ans maintenant que j'arpente dans tous les sens ton oeuvre et m'interroge sur ta vie."

18 "[Decout:] - Gary est l'auteur d'une sorte de "tombeau" pour sa mère avec La Promesse de l'aube, un hommage qui est aussi une résurrection. Pourquoi avoir vous-même choisi ce genre? Avez-vous pensé à l'analogie avec La promesse de l'aube? /[Huston:] - Pas forcément. Le titre n'est venu que dans un second temps. C'est vrai qu'avec l'idée du tombeau, je pensais aussi à Rameau, entre autres. C'était à la fois un hommage et une façon de l'enterrer différemment."
} 
O uso da ironia é extremamente recorrente na escrita da autora: sobretudo em seus ensaios, mas também em seus romances, o viés irônico se associa ao humor e contribui para a desconstrução de ideias (ALMEIDA, 2009). No Tombeau, a ironia está presente ao longo de todo o texto e tem como contraponto o prazer ea reflexão originados na leitura da obra de Romain Gary.

Na mesma entrevista citada acima, a escritora relata sua postura ao escrever esse texto:

[Decout:] - Então, você se sentia romancista, e não crítica literária, ao escrever sobre Gary?

[Huston:] - De fato, eu não me sentia nem um pouco crítica literária. Porque foi mais como ser humano, escritora, exilada e plurilíngue que escrevi esse texto. Foi por causa de uma espécie de sentimento de cumplicidade com Gary (HUSTON, 2014b, p. 240).19

Apesar de não concordar explicitamente com o entrevistador sobre a postura de romancista, ao elencar algumas semelhanças que percebe entre si mesma e Romain Gary, Nancy Huston se aproxima dessa posição. A recusa do posicionamento de crítica literária parece corroborar esse movimento, mas a palavra usada na resposta é "escritora", postura que abrange outras possibilidades, além das propostas pelo entrevistador, sem que uma exclua necessariamente outras. ela já é uma romancista premiada quando escreve o Tombeau, e essa prática também deixa marcas no texto ensaístico. Talvez, este seja o material menos visível ou talvez menos desenvolvido nessa construção, apesar de presente no início e no fim do texto.

A epígrafe escolhida para o Tombeau é uma citação de Romain Gary (apud HUSTON, 1995, p. 9): “A verdade? Que verdade? A verdade talvez seja que eu não existo. O que existe, o que começará a existir, talvez um dia, se eu tiver muita sorte, são meus livros, alguns romances, uma obra, se é que posso usar esse termo. Todo o resto é literatura". ${ }^{\circ 0} \mathrm{E}$ a conclusão do texto retorna a essa

19 "[Decout:] - Vous vous êtes donc senti romancière et non pas critique littéraire en prenant la plume sur Gary? /[Huston:] - En effet, je ne me suis certainement pas sentie critique littéraire. Car c'est plutôt en tant qu'être humain, écrivaine, exilée et plurilingue que j'ai écrit ce texte. C'est à cause d'une sorte de sentiment de complicité avec Gary."

zo "La vérité? Quelle vérité? La vérité est peut-être que je n'existe pas. Ce qui existe, ce qui commencera à exister peut-être un jour, si j'ai beaucoup de chance, ce sont mes livres, quelques romans, une oeuvre, si j'ose employer ce mot. Tout le reste, c'est de la littérature." Essa citação foi retirada de uma entrevista concedida a François Bondy, publicada, originalmente, em 1957 e republicada em 2005 . 
pergunta, com uma possível resposta: "É verdade. Tudo verdade. Roman"21 não morto" (HUSTON, 1995, p. 103). ${ }^{22}$ A própria enunciadora deixa uma pista que sugere a razão da presença discreta do romance no Tombeau: "Ah, Romain... Vendo tua obra - abundante, transbordante, monumental - e tua vida, todas as numerosas vidas pelas quais você ardeu, qualquer romancista só pode se sentir minúsculo, espremido, míope" (p. 97). ${ }^{23} \mathrm{~A}$ admiração pela obra e pelo autor que homenageia em seu texto, de certa forma, impõe limites ao uso do gênero literário mais praticado por Romain Gary.

Para a construção desse túmulo, Nancy Huston recolhe materiais provenientes da biografia, do panegírico, do ensaio e do romance em quantidades diferentes. $\mathrm{O}$ resultado é um texto compósito que promove encontros entre as vozes de Nancy Huston e Romain Gary, mas também com as de Michel Cazenave, La Rochefoucauld e outros que também são citados. Não se trata de um encontro de amigos, mas sim de escritores convidados por Nancy Huston para uma conversa sobre a escrita de Romain Gary. Ao "libertá-la” da crítica marcadamente estruturalista, o escritor e sua obra contribuem para que a ensaísta construa espaços mais amplos, combinando elementos diversos e usando cores menos usuais. Assim, a escrita do Tombeau marca uma mudança nos ensaios da escritora, que adotam um tom de informalidade quase constante, sem relegar, no entanto, estudos e experiências que embasam a reflexão.

\section{O ENSAIO DO AFETO}

Passions d'Annie Leclerc (HUSTON, 2007) é considerado por alguns críticos um livro inclassificável, no que diz respeito ao gênero. Assim como no Tombeau, a edição original não traz nenhum indicativo genérico, mas, nas listas de publicações da autora, que constam nas páginas iniciais ou finais dos volumes de sua obra, o texto sempre é incluído na categoria ensaio. A dificuldade para reconhecer o gênero que melhor definiria o pacto textual

\footnotetext{
${ }^{21}$ A escritora faz um jogo de palavras com o nome que consta na certidão de nascimento de Gary, Roman, e a palavra romance. A grafia Romain foi adotada oficialmente quando ele obteve autorização de mudança de nome, em 9 de outubro de 1951. A partir dessa data, Roman Kacew se torna Romain Gary (BONA, 1987, p. 143).

22 "C'est vrai. Tout vrai. Roman pas mort."

${ }_{23}$ "Oh Romain Au vu de ton oeuvre foisonnante, débordante, monumentale et de ta vie, de toutes les nombreuses vies dont tu brûlas, tout romancier ne peut que se sentir minuscule, étriqué, myope."
} 
decorre, sobretudo, de movimentos de escrita que transitam entre relatos biográficos e autobiográficos, trechos da correspondência entre as duas escritoras - Nancy Huston e Annie Leclerc -, excertos dos diários da autora canadense, construções laudativas que asseguram o esboço do túmulo, reflexões sobre a obra e a personalidade da escritora e filósofa francesa, que percorrem as veredas do ensaio, sopros e lufadas de afinidades e sentimentalidades que alcançam os espaços da ficção.

O texto é dividido em capítulos que remetem a temas recolhidos da obra, da vida, das ideias compartilhadas, dos estudos, dos gostos não compartilhados. Naverdade, esses títulos - em sua grande maioria constituídos por uma só palavra - delineiam uma fotografia daquilo que era importante para Annie Leclerc, de suas paixões, de certa forma. O primeiro e o último capítulos situam-se fora dessa imagem, pois são a introdução - "Connaître quelqu'un" [conhecer alguém] - e a conclusão - "Saluto alla strega” [saudação à feiticeira] - nas quais Nancy Huston se restringe às suas próprias impressões, sem incluir a voz de Annie Leclerc. Antes da relação das obras citadas de Annie Leclerc, a autora inseriu anexos, com trechos de livros da filósofa francesa e com um trecho da filósofa Séverine Auffret, que remete ao enterro de Annie Leclerc.

Na introdução ao volume, Nancy Huston (2007, p. 16) explicita o objetivo do texto:

\begin{abstract}
Assim, nestas páginas, tentarei fazer existir Annie um pouco como um personagem. Para mim, naturalmente, seria fácil empreender pesquisas avançadas sobre sua infância, reunir materiais, interrogar os que lhe eram próximos, reler todos os seus livros, compulsar seus arquivos... mas não farei nada disso. Não agora. Agora, quero falar da Annie que está em mim. ${ }^{24}$
\end{abstract}

A postura da escritora diante de seu texto é fortemente marcada pela afinidade e pela amizade com o tema da escrita. A enumeração de procedimentos preparatórios, que poderiam conferir ao texto um caráter

\footnotetext{
24 "Ainsi, je chercherai dans ces pages à faire exister Annie un peu à la manière d'un personnage. Il me serait naturellement possible d'entreprendre des recherches poussées sur son enfance, de réunir des matériaux, d'interroger ses proches, de relire tous ses livres, de compulser ses archives... mais je ne ferai rien de tout cela. Pas maintenant. Maintenant, je veux parler de l'Annie qui est en moi."

NT: O itálico da autora na palavra maintenant não apenas acentua o momento presente, mas também dialoga com um jogo de palavras que será explicitado alguns capítulos à frente: "Maintenant disaient les mains d'Annie (et dit le mot lui même: maintenant, tenant dans la main)" [Agora diziam as mãos de Annie (e diz a própria palavra: maintenant [agora], segurando na mão)] (p. 139). Na tradução, não foi possível manter esse jogo.
} 
científico, confirma que Nancy Huston está apta a produzir um estudo aprofundado sobre Annie Leclerc. No entanto, ela afirma que não o fará, sinalizando que escolheu o caminho da subjetividade, privilegiando experiências e impressões. Essa postura prepara o leitor para um texto em que lembranças de fatos, encontros e discursos serão elementos constituintes de um retrato da amiga que não conseguiu se curar de um câncer. Passions d'Annie Leclerc se configura como esse retrato, mas, longe de se reduzir a um testemunho de amizade, o texto incorpora os procedimentos recusados pela autora e adentra territórios de diversos gêneros.

Apesar de não seguir um percurso cronológico, Nancy Huston destaca episódios e fatos da vida de Annie Leclerc que realmente ocorreram e que marcam o texto com traços biográficos - o primeiro encontro presencial das duas, as oficinas de leitura e escrita com prisioneiros, as viagens a Creta, as internações hospitalares, dentre outros. Entretanto, essa referencialidade fica esmaecida ao compartilhar espaços com comentários e análises da narradora. Em vários momentos, essas referências confirmam a aproximação de gostos e práticas entre as duas, fortalecendo a ideia de uma amizade baseada também em semelhanças: "sem nos conhecermos, sem falarmos a respeito uma com a outra, sem nem mesmo imaginar que um dia poderíamos conversar sobre isso, Annie e eu íamos separada e assiduamente a presídios" (HUSTON, 2007, p. 82). ${ }^{25}$

Essas semelhanças, em vários momentos, são registradas na correspondência que Nancy Huston e Annie Leclerc trocaram desde que se conheceram pessoalmente, em janeiro de 2000, até o falecimento da filósofa, em outubro de 2006. Os trechos das cartas de Annie Leclerc permitem que o leitor ouça a própria voz da filósofa, da escritora, da amiga, presentificando, de certa forma, a grande homenageada do texto em momentos pessoais, por meio de discursos que não visavam à publicação. Os extratos de cartas de Nancy Huston, naturalmente, desempenham a mesma função, mas também abrem frestas para uma escrita autobiográfica. Ainda sobre as visitas ao presídio, por exemplo, revela a autora:

Diferentemente de todos nós, eles não estão pensando no que têm a fazer "depois"... Eu lhes disse, e é verdade, que me sentia mais eu mesma entre eles

25 "[...] sans se connaître, sans se consulter, sans même imaginer que nous pourrions un jour en discuter ensemble, nous allions, Annie et moi, séparément et assidûment, dans les prisons”. 
do que em uma mesa redonda na universidade ou em um debate literário na

FNAC. (N. H. a. L., 19 de setembro de 200o) (HUSTON, 2007, p. 83). ${ }^{26}$

O relato da observação feita aos prisioneiros tem como referência apenas Nancy Huston, mas a correspondência se refere a uma atividade praticada por ambas e sobre a qual trocam ideias e opiniões. A proximidade entre as duas, a admiração mútua, o reconhecimento da influência de Leclerc na constituição de Huston como escritora são laços cujas pontas, ambas, ficam visíveis no texto. Assim, linhas biográficas e traços autobiográficos se entrelaçam na trama textual.

Essas frestas autobiográficas também são expostas nos sete excertos do diário de Nancy Huston citados no livro. Em um desses trechos, narra a autora:

Quando a noite caiu, eu estava em um estado de agitação raro (até para mim) e fui acalmada, tranquilizada pela expressão autenticamente pesarosa e chocada do rosto de Annie, quando falei sobre o meu desejo de morrer. Ela veio se sentar ao meu lado, acariciou meu cabelo e repetiu, olhando nos meus olhos: "Mas eu gosto de você, eu gosto de você, você faz parte dos seres que trazem luz aos outros. E se você sucumbir às trevas..." ela também disse que não nos cabia representar a totalidade das infelicidades do mundo, ainda que em nós mesmos, pois esse esforço nos derrota e mina nossas forças. (Diário de N. H, 11 de janeiro de 2001) (HUSTON, 2007, pp. 105-106). ${ }^{27}$

Esse extrato é citado para exemplificar a atitude equilibrada de Annie, ou seja, sempre longe dos extremos, e seu impulso de ajudar e consolar. E, de fato, esse objetivo é alcançado. Contudo, o mesmo trecho também expõe um momento de crise aguda de Nancy Huston, registrado em seu diário. Apenas uma fresta, vista de relance, um fio autobiográfico no texto sobre Annie Leclerc.

Passions não se restringe, entretanto, aos vieses biográficos e autobiográficos. A homenagem evidente à amiga falecida também é tecida

\footnotetext{
26 'À la différence de nous tous, ils ne sont pas en train de penser à ce qu'ils ont à faire 'après'.. Je leur ai dit, et c'est vrai, que je me sentais plus moi-même parmi eux que dans une table ronde à l'université ou un débat littéraire à la FNAC. (N. H. à A. L., 19 septembre 200o)."

${ }_{27}$ "Le soir arrivé, j'étais dans un état d'agitation rare (même pour moi) et j’ai été calmée apaisée par l'expression de chagrin et de choc authentique sur le visage d'Annie quando je lui ai parlé de mon désir de mourir. Ele est venue s'asseoir à mes côtés, m’a caressé les cheveux et a répété, en me regardant dans les yeux: 'Mais je t’aime, mais je t’aime, mais tu fais partie des êtres qui donnent de la lumière aux autres. Et si toi, tu succombes aux ténèbres...' Elle a dit aussi qu'il ne nous incombait pas de représenter la totalité des malheurs du monde, serait-ce en nous-mêmes, car cet effort-là nous défait et sape nos forces. (Journal de N. H., 11 janvier 2001)."
} 
com elogios à obra e à personalidade de Annie Leclerc. Na verdade, o caráter laudativo desse texto é muito mais vigoroso do que o que encontramos no Tombeau, o que nos remete ao gênero túmulo. Apesar de não constar no título nem no peritexto do livro, esse gênero é bastante presente nele.

Contudo, se o Tombeau, no dizer de Nancy Huston, é um outro tipo de enterro para Romain Gary, em Passions, vemos o movimento contrário: a obra de Annie Leclerc é revisitada, para alguns, e apresentada para boa partedos leitores de Nancy Huston. Com efeito, em 2007, ano de publicação de Passions, a autora canadense já tem uma carreira consolidada: vários romances receberam prêmios literários na França e no Canadá, suas publicações são bastante regulares e seus livros, traduzidos em algumas línguas. ${ }^{28}$ Annie Leclerc, por sua vez, é menos conhecida do público: sua obra é constituída, majoritariamente, de ensaios. ${ }^{29} \mathrm{O}$ sucesso de Parole de femme, de 1974, parece não ter se repetido ao longo de sua carreira, mas a filósofa é frequentemente citada em textos sobre feminismo, condição da mulher, estudos de gênero.

A polêmica suscitada pelo ensaio de $1974,{ }^{30}$ alinha o posicionamento de Annie Leclerc ao das teóricas do feminismo e militantes do Movimento pela Liberação da Mulher (MLF), que são classificadas como diferencialistas, em oposição às universalistas (MACHADO, 1998). No primeiro campo, encontram-se Luce Irigaray, Hélène Cixous, Julia Kristeva, ${ }^{31}$ enquanto no campo das universalistas, a figura central ainda é Simone de Beauvoir. A polêmica custou a Annie Leclerc o afastamento do grupo de intelectuais ligados a Jean-Paul Sartre e Simone

${ }^{28}$ De 1979, início de sua carreira, a 2007, ou seja, em 29 anos de publicações, Nancy Huston não publicou livros apenas nos anos 1983, 1987, 1988 e 1991. São 11 romances, 1 peça de teatro, 11 ensaios (incluindo 2 coletâneas), 2 livros de correspondência, 5 livros em coautoria com artistas e 3 livros infanto-juvenis. Os romances Cantique des plaines (1993), La virevolte (1994), Instruments des ténèbres (1996), L'empreinte de l'ange (1999), Dolce agonia (2002) e Lignes de faille (2006) receberam prêmios literários. Em 2007, a autora tinha livros traduzidos em inglês, alemão, italiano, espanhol, português, grego e japonês.

29 De 1967 a 2003, Annie Leclerc publicou 13 livros, dos quais um em coautoria. Postumamente, foram publicados os ensaios inacabados L'amour selon Mme de Rênal, de 2007, e Paedophilia ou l'amour des enfants, 2010, ambos com prefácio e organização de Nancy Huston, e Variations sur des thèmes de Gould, 2007, em coautoria com Ghislayne Guertin, Michèle Terrien e Georges Guillard.

${ }^{30}$ Nesse ensaio, Annie Leclerc propõe uma nova visão do feminino, baseada em uma identidade feminina que deve ser construída. Essa proposta se opõe à visão de Simone de Beauvoir, ícone do feminismo, que defende a igualdade total entre homens e mulheres.

${ }^{31}$ Essas pensadoras têm propostas que as aproximam desse campo, mas não, militância nessa linha. 
de Beauvoir, e à revista Les Temps Modernes. Nancy Huston se aproxima do viés diferencialista ainda na década de 1970 e, em Passions, resgata a polêmica e ratifica a posição de Annie Leclerc. O caráter laudativo do texto é sustentado por uma reflexão bastante amadurecida, que ingressa no espaço ensaístico. O túmulo de Annie Leclerc, na verdade, desenterra a obra da filósofa e escritora, iluminando-a postumamente.

No conjunto de ensaios da escritora canadense, temas ligados ao MLF, ao feminismo, à condição feminina, às peculiaridades do gênero feminino, especialmente, à maternidade, à valorização de atividades outrora consideradas essencialmente femininas, à exploração do corpo e de um ideal feminino, definido e defendido sobretudo por homens, são recorrentes e, às vezes, exaustivamente abordados. Em Passions d'Annie Leclerc, essas questões estão no fulcro do texto, tendo como ponto equivalente apenas a amizade. Na verdade, as reflexões sobre o feminino e sobre o afeto entre as duas ensaístas e escritoras estão fortemente imbricadas e se alternam nas posições de causa e efeito, busca e resultado. Assim como Romain Gary teria libertado Nancy Huston dos estudos literários excessivamente estruturalistas, Annie Leclerc a liberta de um feminismo que, de certa forma, encarcera um feminino que Nancy Huston (2007, p. 117) defenderá ardorosamente, como declara:

Se eu não tivesse lido Parole de femme, com suas páginas impressionantes sobre o parto (coisa que, até então, me aterrorizava), e seu elogio sincero dos gestos domésticos, da cozinha, dos cuidados com os corpos e os lugares... é bem possível que eu nunca tivesse me tornado mãe, nem romancista. Pois ser romancista é, também, aceitar a vida material, entrar direto nos detalhes do cotidiano, perscrutar, sorver e tocar sem nojo a poeira e as vassouras, as camas desfeitas e os filhos que choram, as carnes e os legumes, as mil contradições que circulam no interior de cada família: dores, risos, transmissões, traições... ${ }^{32}$

No espaço ensaístico, Nancy Huston argumenta em favor da prática de atividades e da incorporação de papéis que o movimento feminista havia identificado como marcas da opressão da mulher. É importante

\footnotetext{
32 "Si je n'avais pas lu Parole de femme, avec ses pages inouïes sur l'accouchement (chose qui, jusque-là, me terrifiait), et son éloge sincère des gestes du ménage, de la cuisine, des soins d'entretien des corps et des lieux... il se pourrait très bien que je ne sois jamais devenue mère, ni romancière. Car être romancière aussi, c'est accepter la vie matérielle, entrer de plan-pied dans le détail du quotidien, scruter, humer et toucher sans dégoût la poussière et les balais, les lits défaits et les enfants qui pleurent, les viandes et les légumes, les mille contradictions qui circulent à l'intérieur de chaque famille: douleurs, rires, transmissions, trahisons..."
} 
observar que se trata de atividades - e não de tarefas - que geram prazer, o que subverte a ideia de confinamento da mulher ao espaço interno da casa, doméstico, e a consequente exclusão dos espaços externos de atuação feminina. Ambas as pensadoras propõem o resgate de um direito que teria sido equivocadamente confiscado às mulheres em nome da liberação e da equiparação de direitos entre os sexos.

Esse compartilhamento de opiniões em relação a algumas posições feministas teve início no fim da década de 1970, quando ambas escreviam artigos para a revista Sorcières, sem se conhecerem pessoalmente. Nessa época, a jovem estudante Nancy Huston está bastante interessada na vertente estruturalista dos estudos literários e no MLF. Annie Leclerc é uma escritora e filósofa já conhecida, com alguns ensaios e um romance publicados. $\mathrm{O}$ encontro entre as duas só ocorrerá em 2000 e marcará o início de uma amizade profunda:

Para mim, é fácil e delicioso deslizar até aquele dia da metade de janeiro de 2000 , quando bati pela primeira vez à porta verde de sua casa, em uma travessa do bairro da Butte-aux-Cailles.

Desde esse primeiro encontro, para dizer a verdade desde os primeiros instantes desse primeiro encontro, passamos aos lamentos e a nos tratar de você. Uma amizade é o que acontece quando cada um reconhece tranquilamente tanto as forças do outro quanto suas próprias fraquezas (HUSTON, 2007, pp. 35-36).33

Essa amizade natural, agradável, duradoura, atravessa o texto com relevos e cores que constituem o principal motivo desse tecido. O resgate da obra, a defesa das posições, a narrativa dos sofrimentos, a lembrança dos sorrisos, a publicação de trechos de cartas, a análise e o elogio da produção ensaística e ficcional, a exposição das qualidades são fios que se entrelaçam com a dor da perda da amiga. Esse entrelaçamento de textos, estudos e sentimentos produz um ensaio não sobre o afeto, mas sim, do afeto que habita Nancy Huston.

\footnotetext{
33 "Il m’est facile et délicieux, de me glisser dans cette journée de la mi-janvier 200o, quand j'ai frappé à la porte verte de sa maison, dans un passage du quartier de la Butte-aux-Cailles. /Dès cette première rencontre, à vrai dire dès les premiers instants de cette première rencontre, on est passées au tu, et aux plaintes. Une amitié, c'est ce qui arrive lorsque chacun reconnaît tranquillement tant les forces de l'autre que ses propres faiblesses."
} 


\section{ENSAIANDO CONCLUSÕES}

Na produção ensaística de Nancy Huston, o gênero ensaio é reiteradamente revisto por meio de uma escrita que ultrapassa limites, subverte conceitos, restaura procedimentos e investe em novas composições. Essa renovação e reelaboração do espaço ensaístico retomam reflexões importantes sobre o ensaio sem, no entanto, propor uma (re)conceituação do gênero. Nesse sentido, podemos observar, por exemplo, que o resgate da etimologia do termo, sugerido por Starobinski (2011), que aponta para a oscilação entre exame e enxame, é bastante pertinente no corpus que utilizamos. O conhecimento profundo das obras de Romain Gary e Annie Leclerc é condição fundamental para a escrita desses ensaios. Mas a transformação de ambos em personagens seus, outorgando-se uma liberdade guiada pela certeza de conhecê-los melhor do que pessoas que conviveram com o escritor - que a autora não conheceu pessoalmente ou que tiveram mais tempo de convivência com a filósofa - com quem Nancy Huston conviveu por pouco mais de seis anos - aproxima-se do lado enxame do ensaio, pois abre caminho para um pulular de ideias que não apenas enriquece o texto, mas também o constitui como espaço de reflexão experimental.

Ela também resgata, tanto em Tombeau de Romain Gary quanto em Passions d'Annie Leclerc, a pergunta que Roland Barthes (1988, p. 284) indica como definidora do caráter metafórico do ensaio: $\mathrm{O}$ que isso quer dizer?, e adapta: O que obra e vida de Romain Gary querem dizer? O que obra e vida de Annie Leclerc querem dizer? Essa pergunta inicial é seguida por outra que adentra o campo metonímico, no qual Barthes localiza o romance: Como continuar? Contudo, a escrita ensaística de Nancy Huston não é urdida entre uma aparente oposição simples. Na verdade, no tecido ensaístico, a escritora cose retalhos de biografias e autobiografias, borda epitáfios, costura trechos de cartas e diários e alinhava vieses ficcionais. Essa escrita matizada e compósita cruza limites e alarga fronteiras, problematizando e redefinindo seus espaços.

Em nosso corpus, esses trechos de textos de outros gêneros são inseridos com linhas tingidas de humoreafeto. No Tombeau, a ironia que oscila entre mordacidade e cumplicidade, entre divergência e compartilhamento também destaca momentos de divertimento. Em Passions, a forte ligação afetiva entre a autora e seu tema sublinha tempos de leveza e sofrimento, de diversão e tristeza. Em ambos, fica impressa a opção por uma ludicidade que corrobora o prazer da escrita. Esse trabalho de rejunte e cosedura 
não se encerra quando está completo, mas sim, quando o conjunto se mostra suficientemente coerente no edifício inacabado e na trama em fragmentos. Essa escrita livre, que não se acomoda em limites, mas, ao contrário, hesita em idas e vindas entre os lados, ocupa, segundo Adorno (2003), um lugar entre os “despropósitos". Esse descompromisso que, para Lukács (2008), está mais próximo de uma autonomia, é uma escolha da autora para tratar alguns temas para os quais o texto substancialmente ficcional parece não ser a alternativa satisfatória. Romain Gary e Annie Leclerc, enquanto personagens de Nancy Huston, poderiam fazer parte de romances, gênero em que ela tem desenvoltura. Porém, o terreno movente e fluido do ensaio, no qual o eu se apresenta de modo mais explícito, parece ser o caminho mais pertinente para uma reflexão livre, que se serve de formas heterogêneas e que transita em diferentes percursos genéricos.

No espaço ensaístico, a autora assina uma escrita marcada por um subjetivismo consciente. O estudo da obra de Romain Gary e de Annie Leclerc é o ponto de partida para reflexões que ultrapassam a dimensão literária. Guiada pelojuízo, "instrumentoútil em tudo", segundo Montaigne (1996, p. 266), Nancy Huston passeia pela obra, por pensamentos e por atitudes de escritores que, de acordo com a própria autora contribuíram decisivamente para sua reflexão e para sua constituição como escritora. Ambos, Romain Gary e Annie Leclerc, são apresentados como libertadores, respectivamente, do estruturalismo literário e do feminismo universalista, eadmirados pelos percursos que seguiram e pelos resultados que produziram. Nesse sentido, os ensaios são espaços de encontros. Não se trata, apenas, de estudos sobre grandes nomes, mas também de trocas com ideias e propostas corroboradas ou refutadas, com trechos de escritos que se completam ou se apartam. Nesse espaço, o texto de Nancy Huston, em alguns momentos, também se torna uma resposta à pergunta feita pelo texto do outro (JAUSS, 1988), atualizada e incorporada em sua própria obra. As diferentes vozes que ecoam nesses ensaios contribuem para a ratificação de um ambiente dialógico (ALMEIDA, 2004) no qual a autora conversa com personagens e textos.

Esses espaços de encontros apresentam, entretanto, configurações bastante diferentes. No Tombeau, as paredes do edifício oferecem um lugar de trocas crítico-literárias entre pares. O que ultrapassa esse limite não vai muito além do contexto da vida do escritor. Impressões, sentimentos e emoções estão presentes, mas de forma contida. Em Passions, o lugar é marcadamente feminino e artesanal. As costuras 
e bordados são executados por mulheres que compartilham leituras, críticas, reflexões, tristezas, alegrias, atividades domésticas, afetividades. Esse trabalho de artesanato corrobora o posicionamento das duas amigas em relação à atuação da mulher na sociedade: o âmbito doméstico não é uma exclusividade nem uma obrigatoriedade da mulher, mas sim uma inclusividade e uma possibilidade que não lhe podem ser negadas.

Esses espaços ensaísticos, construídos por Nancy Huston, também se configuram como percursos de descoberta. Para além das conclusões advindas da análise da obra e da escrita sobre a obra, a reflexão produzida favorece o estabelecimento de relações com os textos da autora e promove a construção de novas interfaces e o avanço no pensamento. Assim, por exemplo, afirma a autora, em Tombeau de Romain Gary:

Dessa forma, a série de contradições evocada no início desse percurso se dissolve por si mesma: sim, como você, Romain, somos todos metecos bastardos jogados na terra sem a menor razão, para nos debatermos para sempre entre o nobre e o ignóbil, a graça e a desgraça que habitam em nós (HUSTON, 1995, p. 101).34

Também em Passions d'Annie Leclerc, Nancy Huston (2007, p. 275) explicita o percurso de descoberta:

Cada vez mais claramente, parece-me que, à medida que avanço na escrita desse livro, que, na época em que a conheci - sim, ao longo de toda essa época, esses poucos anos de descanso entre dois ataques da doença -, Annie Leclerc se preparava para morrer. ${ }^{35}$

Essa dimensão heurística, embora seja peculiar à escrita ensaística, tem marcas particularmente visíveis no corpus que estudamos. As diferentes costuras, a pluralidade de vozes, os numerosos deslocamentos entre os gêneros, os importantes encontros no espaço ensaístico, concorrem de modo determinante para agudizar esse caráter heurístico que inclui atalhos de autodescoberta.

Enquanto espaços de encontros, esses ensaios de Nancy Huston também são grifados por demonstrações explícitas dos sentimentos da

\footnotetext{
34 "Ainsi la série de contradictions évoquée en début de parcours s’évanouit-elle d’elle-même: oui, comme toi, Romain, nous sommes tous des bâtards métèques flanqués sur terre sans la moindre raison, pour nous débattre à jamais entre le noble et l'ignoble, la grâce et la disgrâce qui nous habitent."

35 "Il m’apparaît de plus en plus clairement, à mesure que j'avance dans l'écriture de ce texte-ci, qu'à l'époque où je l'ai connue - oui, tout au long de cette époque, ces quelques années de répit entre deux ataques de la maladie, Annie Leclerc se préparait à mourir."
} 
autora em relação aos escritores que transforma em texto. Análise arguta, crítica fina, elogio sensível, sensações reveladas, uma escrita que testa limites, revisita sentidos e experimenta caminhos. Recusando escolhas reducionistas em muitas esferas de sua vida - canadense ou francesa? Romancista ou mãe? -, Nancy Huston faz do ensaio um espaço com múltiplas possibilidades e poucos limites.

\section{REFERÊNCIAS}

ADORNO, Theodor W. O ensaio como forma. In: Notas de literatura I. Trad. Jorge de Almeida. São Paulo: Duas Cidades / Editora 34, 2003, pp. 15-45.

ALMEIDA, Claudia. O túmulo aberto: Nancy Huston relendo Romain Gary. Tese (Doutorado em Letras Neolatinas - Literatura Francesa e Literaturas de Língua Francesa) - Faculdade de Letras, UFRJ, Rio de Janeiro, 2004.

ALMEIDA, Claudia. A construção do ethos intelectual nos ensaios de Nancy Huston. Ipotesi, v. 13, 2009, pp. 41-52.

ANGENOT, Marc. Remarques sur l'essai littéraire. In: DUMONT, François (org.). Approches de l'essai (Anthologie). Quebec: Nota Bene, 2003, pp. 137-157.

BARTHES, Roland. Aula. 14 $4^{\underline{a}}$ ed. Trad. de Leyla Perrone Moysés. São Paulo: Cultrix, [s.d.]. Disponível em: <https://edisciplinas.usp.br/pluginfile.php/160637/mod_resource/ content/1/BARTHES_Roland_-_Aula.pdf>. Acesso em: 20 mar. 2017.

BARTHES, Roland. Durante muito tempo fui dormir cedo. In: O rumor da língua. Trad. de Mario Laranjeira. São Paulo: Brasiliense, 1988, pp. 283-294.

BONA, Dominique. Romain Gary. Paris: Mercure de France, 1987.

GARY, Romain. Le moment de vérité (Entrevista). In: HANGOUËT, Jean-Paul; AUDI, Paul (orgs.). L'affaire homme. Paris: Gallimard, 2005.

GARY, Romain. Promessa ao amanhecer. Trad. de Mauro Pinheiro. São Paulo: Estação Liberdade, 2008.

GENETTE, Gérard. Figures V. Paris: Seuil, 2002.

HOUAISS, Antonio; VILLAR, Mauro de Salles. Dicionário Houaiss da Língua Portuguesa. Rio de Janeiro: Objetiva, 2001.

HUSTON, Nancy. Jouer au papa et à l'amant. De l'amour des petites filles. Paris: Ramsay, 1979.

HUSTON, Nancy. Trois fois septembre. Paris: Seuil, 1989. 
Remate de Males, Campinas-SP, v. 37, n. 2, p. 613-638, jul./dez. 2017 - 637

HUSTON, Nancy. Journal de la création. Paris: Seuil, 1990.

HUSTON, Nancy. Tombeau de Romain Gary. Arles / Montréal: Actes Sud / Leméac, 1995.

HUSTON, Nancy. Lire, mar. 2001, pp. 30-35. Entrevista concedida a Catherine Argand.

HUSTON, Nancy. Passions d’Annie Leclerc. Arles / Montréal: Actes Sud / Leméac, 2007.

HUSTON, Nancy. Romain Gary, l'insaisissable avec Nancy Huston (Emissão radiofônica). France Inter, 13 jun. 2014a. Entrevista concedida a Zoé Varier. Disponível em: <https://www.franceinter.fr/emissions/l-heure-des-reveurs/l-heure-des-reveurs-13juin-2014>. Acesso em: 24 mar. 2017.

HUSTON, Nancy. Une chambre d'échos sans fin. Europe, n. 1.022-1.023, juin-juillet 2014b, pp. 238-243. Entrevista concedida a Maxime Decout.

HUSTON, Nancy; KINSER, Samuel. A l'amour comme à la guerre. Correspondance. Paris: Seuil, 1984 .

JAUSS, Hans Robert. Pour une herméneutique littéraire. Paris: Gallimard, 1988.

KRISTEVA, Julia. Comment parler à la littérature avec Roland Barthes (Conferência). “Colóquio Avec Roland Barthes”, Paris, Collège de France, 2015. Disponível em: <http://www.college-de-france.fr/site/antoine-compagnon/symposium-2015-11-13oghi5.htm>. Acesso em: 21 mar. 2017.

LANGLET, Irène. Les théories de l'essai littéraire dans la seconde moitié du XXe siècle. Domaines francofone, germanophone et anglophone. Synthèses et enjeux. Université de Rennes 2, Haute Bretagne, 1995. Disponível em: <https://hal-unilim.archivesouvertes.fr/tel-01246913/document>. Acesso em: 10 mar. 2017.

LUKÁCS, G. Sobre a essência e a forma do ensaio: uma carta a Leo Popper. Trad. de Mario Luiz Frungillo. Revista UFG, n. 4, jun. 2008. Disponível em: <https://projetos.extras. ufg.br/joomla_proec/revista_ufg/junho20o8/Textos/essenciaFormaEnsaio.pdf>. Acesso em: 9 mar. 2017.

MACHADO, Lia Zanotta. Gênero, um novo paradigma? Cadernos Pagu, n. 11, 1998, pp. 107-125. Disponível em: <http://periodicos.sbu.unicamp.br/ojs/index.php/cadpagu/ article/view/8634467>. Acesso em : 4 abr. 2017.

MONCOND’HUY, Dominique (org.). Le tombeau poétique en France. La Licorne, "Le tombeau poetique en france", Poitiers, n. 29, 1994, pp. 3-16.

MONTAIGNE, Michel de. Ensaios. 2 v. Trad. Sérgio Milliet. São Paulo: Editora Nova Cultural, 1996. (Coleção Os Pensadores)

OBALDIA, Claire de. L'esprit de l'essai. De Montaigne à Borges. Trad. do inglês por Émilie Colombani. Paris: Seuil, 2005. 
SEBBAR, Leïla; HUSTON, Nancy. Lettres parisiennes: autopsie de l'exil. Bernard Barrault, 1986.

STAROBINSKI, Jean. É possível definir o ensaio? Trad. Bruna Torlay. Remate de Males, v. 31, n. 1-2, 2011, pp. 13-24.

VAN TIEGHEM, Philippe. Dictionnaire des littératures. Paris: PUF, 1984.

TERRASSE, Jean. L'essai ou le pouvoir des mythes. In: DUMONT, François (org.). Approches de l'essai (Anthologie). Quebec: Nota Bene, 2003, pp. 105-135.

TIEDEMANN, Rolf. Notas do organizador da edição alemã. In: ADORNO, Theodor. Notas de Literatura I. Trad. Jorge de Almeida. São Paulo: Duas Cidades / Editora 34, 2003, pp. 163-164.

VIGNEAULT, Robert. L'écriture de l'essai. Montréal: Hexagone, 1994. 